\title{
ANNA HOWARTH E AS GUERRAS DAS FRONTEIRAS: LITERATURA, LEI DE TERRAS E COLONIALISMO EM SWORD AND ASSEGAI (ÁFRICA DO SUL, DÉCADA DE 1890)
}

\author{
Evander Ruthieri da Silva ${ }^{1}$
}

\begin{abstract}
Resumo: O período entre as décadas de 1870 e 1890 marcou um contexto de transformações sociais e políticas nos territórios localizados ao sul da África, ocasionadas pela expansão econômica e territorial decorrente das atividades na mineração e agricultura. Diversas medidas foram adotadas pelo colonato branco com o objetivo de controlar as terras ancestrais e a mão de obra da população negra, em especial, a legislação de terras. Diante desse quadro, o artigo concentra-se em Sword and Assegai (1899), de Anna Howarth, um romance de aventura ambientado nas "guerras das fronteiras" da região oriental da Colônia do Cabo (atualmente África do Sul) entre as décadas de 1830 a 1850. O destaque recai na caracterização dos guerreiros Xhosa, compreendendo a ênfase da romancista no "barbarismo" como uma forma de legitimação pública das práticas políticas coloniais, em especial, da apropriação de terras africanas empreendida pela elite colonial.

Palavras-chave: História e Literatura. África do Sul. Colonialismo.

\section{ANNA HOWARTH AND THE FRONTIER WARS: LITERATUR, LAND LEGISLATION AND COLONIALISM IN SWORD AND ASSEGAI (SOUTH AFRICA, 1890s)}

\begin{abstract}
The period between the 1870s and 1890s marked a context of social and political changes in southern Africa, caused by economic and territorial expansion resulting from mining and agriculture activities. Several measures were adopted by white colonizers in order to control African ancestral lands and workforce, such as by land legislation. Within this context, the article focuses on Anna Howarth's Sword and Assegai (1899), an adventure novel set during the "Frontier Wars" of the eastern region of Cape Colony (today part of South Africa), between the $1830 \mathrm{~s}$ and 1850s. The article emphasizes the depiction of Xhosa warriors, specially the novelist's emphasis on "barbarism" as a form of public legitimization for colonial political practices, that is, the appropriation of African lands by the colonial elite.
\end{abstract}

Keywords: History and Literature. South Africa. Colonialism.

\section{ANNA HOWARTH Y LAS GUERRAS FRONTERIZAS: LITERATURA, LEGISLACIÓN AGRARIA Y COLONIALISMO EN SWORD AND ASSEGAI (SUDÁFRICA, DÉCADA DE 1890)}

Resumen: El período comprendido entre las décadas de 1870 y 1890 marcó un contexto de cambios sociales y políticos en los territorios ubicados en el sur de África, provocados por la expansión económica y territorial derivada de las actividades mineras y agrícolas. La colonización blanca adoptó varias medidas para controlar las tierras ancestrales y la fuerza laboral de la población negra, en particular, la legislación agraria. En este contexto, el artículo se centra en Sword and Assegai (1899), de Anna Howarth, una novela de aventuras ambientada en las "guerras fronterizas" de la región oriental de Cape Colony (actualmente Sudáfrica) entre la década de 1830 y 1850. El énfasis es sobre la caracterización de los guerreros Xhosa, entendiendo el énfasis del novelista en la "barbarie" como una forma de legitimación pública de

\footnotetext{
1 Professor adjunto de História da África na Universidade Federal da Integração Latino-America (UNILA). Doutor em História pela Universidade Federal do Paraná (UFPR), com período de doutoradosanduíche na University of Exeter (Reino Unido). E-mail para contato: evander.silva@unila.edu.br.
}

Revista Escritas do Tempo - v. 3, n. 8, mai/ago 2021 - p. 30-50 
las prácticas políticas coloniales, en particular, la apropiación de tierras africanas por parte de la élite colonial.

Palabras clave: Historia y Literatura; Sudáfrica; colonialismo.

\section{Introdução}

O período entre as décadas de 1870 e 1890 marcou um contexto de transformações sociais e políticas nos territórios localizados ao sul da África, ocasionadas, entre outros fatores, pela expansão econômica e territorial decorrente das descobertas de minas de ouro e diamantes. Esse momento histórico envolveu um esforço cumulativo, por parte da elite colonial e do colonato branco, na formulação de códigos jurídicos e leis de terra que garantissem um controle mais efetivo da população negra na África Austral, para fornecer um fluxo constante de mão-de-obra barata e acessível, a ser explorada na mineração ou na agricultura, bem como expropriar as terras ancestrais por meio da desarticulação do seu uso comunal.

Tais medidas fizeram parte de um conjunto mais amplo de práticas políticas adotadas pelo Estado colonial ao sul da África, em especial, na Colônia do Cabo, onde várias medidas começaram a ser engendradas pelo governo local para limitar os direitos políticos e sociais da população negra. Em especial, destaca-se o Glen Grey Act de 1894, idealizado pelo então primeiro-ministro e "magnata" da mineração no sul da África, Cecil Rhodes, com a intenção de pôr um fim ao uso comunal das terras ancestrais de africanos negros, sobretudo das populações Xhosa Gcaleka e Ngqika que habitavam a província oriental da Colônia do Cabo. A lei de 1894 acarretou não apenas em perdas econômicas para aqueles que por ela foram afetados, como também perdas culturais e identitárias, pela negação aos espaços de comunidade e ancestralidade.

Por volta desse período, a enfermeira e romancista Anna Howarth (1854-1943) migrou para a parte oriental da Colônia do Cabo, onde escreveu e publicou uma série de romances ambientados nos territórios sul-africanos. A atenção especial do artigo incide sobre Sword and Assegai, publicado em 1899, com destaque para a caracterização da ação guerreira dos Xhosa, povos de língua e cultura $\mathrm{Nguni}^{2}$, na narrativa literária,

\footnotetext{
${ }^{2}$ Os povos de língua e cultura Nguni habitam regiões da África meridional, principalmente a África do Sul, o reino de Eswatini e o Zimbábue. São pertencentes ao grupo de populações falantes das línguas Bantu, que migraram da África Central rumo a outros pontos do continente há milhares de anos. Entre os Nguni, inclui-se principalmente os Xhosa, os Swazi, os Zulu e os Ndebele, entre outros. Os Xhosa possuem uma associação histórica com a região oriental do Cabo e, desde o século XVIII, estão divididos, por laços de ancestralidade e linhagem, em dois subgrupos principais: os Gcaleka e os Rarhabe (PEIRES, 1982). Outros grupos que partilham da língua e da cultura Xhosa incluem os abaThembu e os amaMpondo. Segundo Gabriela Aparecida dos Santos, no século XIX, o termo "Nguni" também era
} 
contraposta ao contexto político e social decorrente da aprovação da legislação segregacionista e das leis de terras. Política colonial e literatura são palavras chaves para a problematização da fonte em questão, um romance de aventura ambientado entre as décadas de 1830-1850, período de expansão das fronteiras do território colonial no Cabo Oriental, no qual Howarth, alinhando-se aos interesses do colonato expressos na legislação da época, constrói uma narrativa favorável à tomada de terras ancestrais dos Xhosa.

\section{Uma enfermeira britânica no veld sul-africano}

As informações concernentes à trajetória de Anna Howarth são escassas. Sabe-se que, após a morte de seu pai, um capelão na paróquia de Saint George em Londres, a família enfrentou dificuldades financeiras, as quais podem ter condicionado a escolha de Howarth em migrar para o sul da África, especificamente para a porção oriental da Colônia do Cabo. Solteira e sem filhos, Howarth iniciou sua atuação no campo da enfermagem em Grahamstown; posteriormente, passou a viver na fazenda da família de uma de suas pacientes, Selina Kirkman, no assentamento de Steytlerville.

Foi aí que, entre 1895 e 1902, Howarth escreveu e publicou quatro romances ambientados no interior sul-africano, nos quais elabora uma série de reflexões acerca da formação da sociedade colonial: Jan: An Afrikander (1897), Katrina: A Tale of the Karoo (1898), Sword and Assegai (1899) e Nora Lester (1902). Além desses romances, Howarth remeteu diversos artigos e poemas à imprensa periódica em Londres, utilizando, em alguns casos, de um pseudônimo: "Anglo-Africana" (HOWARTH, 1902).

Os contextos de atuação e produção escrita de Anna Howarth podem ser compreendidos a partir de uma relação simbiótica entre "biografia e contexto" (LEVI, 2005, p. 175), pela valorização do entorno histórico do qual a romancista fez parte. Desde a década de 1870, a Colônia do Cabo, parte das posses britânicas na África, havia estabelecido um sistema político semiautônomo, com eleições locais e administração própria, e um primeiro-ministro responsável pelo parlamento, o que limitava a autoridade do governador colonial. Portanto, de um lado, configuravam-se interesses majoritariamente baseados na política local da elite colonial no Cabo e, de outro, as demandas imperialistas, advindas do secretariado de colônias em Londres. No Cabo, 
predominava um sistema eleitoral que garantia direito ao voto a qualquer homem adulto, independentemente da cor, sob a condição que o eleitor fosse detentor de renda anual equivalente a $£ 25$. Porém, a despeito dos apologistas à "tradição liberal do Cabo", cumpre enfatizar que uma série de medidas legislativas foram tomadas, entre as décadas de 1870 e 1890, com o objetivo de restringir os direitos políticos de sul-africanos negros, o que culminou com o registro de raça no título de eleitor em 1893.

Além disso, a "política nativa" mudou drasticamente a partir de 1871, quando a colônia anexou a Basutolândia. As autoridades do Cabo, com base na crença de que os Basoto não estavam "suficientemente avançados em progresso civilizatório e social" para serem assimilados enquanto cidadãos, rejeitaram a cidadania, o que então havia sido comum no modelo "liberal" da colônia. As resistências armadas dos povos Xhosa nesse contexto, especialmente dos seus dois principais grupos - os Gcaleka e Rarhabe (Ngqika) - entre 1877 e 1878, e dos Basoto em 1880 a 1881, levaram os legisladores do Cabo a preservar traços da autoridade das lideranças nativas na forma de conselhos locais, com a intenção de manter, mesmo que indiretamente, o controle colonial.

Governo indireto sobre as populações nativas foi estabelecida no final do século, por meio de um dualismo legal-jurídico que incorporou as leis costumeiras visando um controle mais efetivo sobre a população negra. No Cabo, os parâmetros da sociedade civil visavam incluir uma minoria de nativos, embora, assim como na vizinha Colônia de Natal, segregação e lei costumeira atuavam para separar brancos e negros: em Natal, entre "nativos" e "não-nativos"; no Cabo, entre aqueles considerados "civilizados" e “incivilizados” (MAMDANI, 1996, p. 62-71).

No momento em que Howarth migrou para o Cabo Oriental, pouco restava do período turbulento que havia marcado o processo de demarcação das fronteiras naquela região, as chamadas "guerras das fronteiras" (ou "guerras Anglo-Xhosa"), motivadas pelos conflitos entre o avanço das políticas coloniais e as lutas de reinos e linhagens Xhosa pela preservação de sua autonomia política, controle de terras e gado. A última de uma série de nove guerras havia se encerrado em 1879, marcando o fim da independência dos Gcaleka, o último núcleo Xhosa independente localizado entre o rio Nciba (Kei) e o rio Mbhashe.

A região do Cabo Oriental, previamente vista como uma peça importante na economia sul-africana, mormente pelas atividades agrárias e pelo pastoreio, gradativamente perdeu espaço para a mineração, sobretudo nos territórios bôeres do Transvaal e do Estado Livre de Orange (FOURIE, 1995, p. 70). Desde a descoberta das 
minas de diamantes na Griqualândia em 1867 e em Kimberley em 1870, e do ouro no Transvaal em 1886, profundas e significativas transformações afetaram a economia no sul da África, com o escoamento de capital industrial e uma preocupação constante com o controle das terras e da mão de obra africana (KANIKI, 2010) ${ }^{3}$.

Figura 1 - Mapa do sul da África (1850-1880)

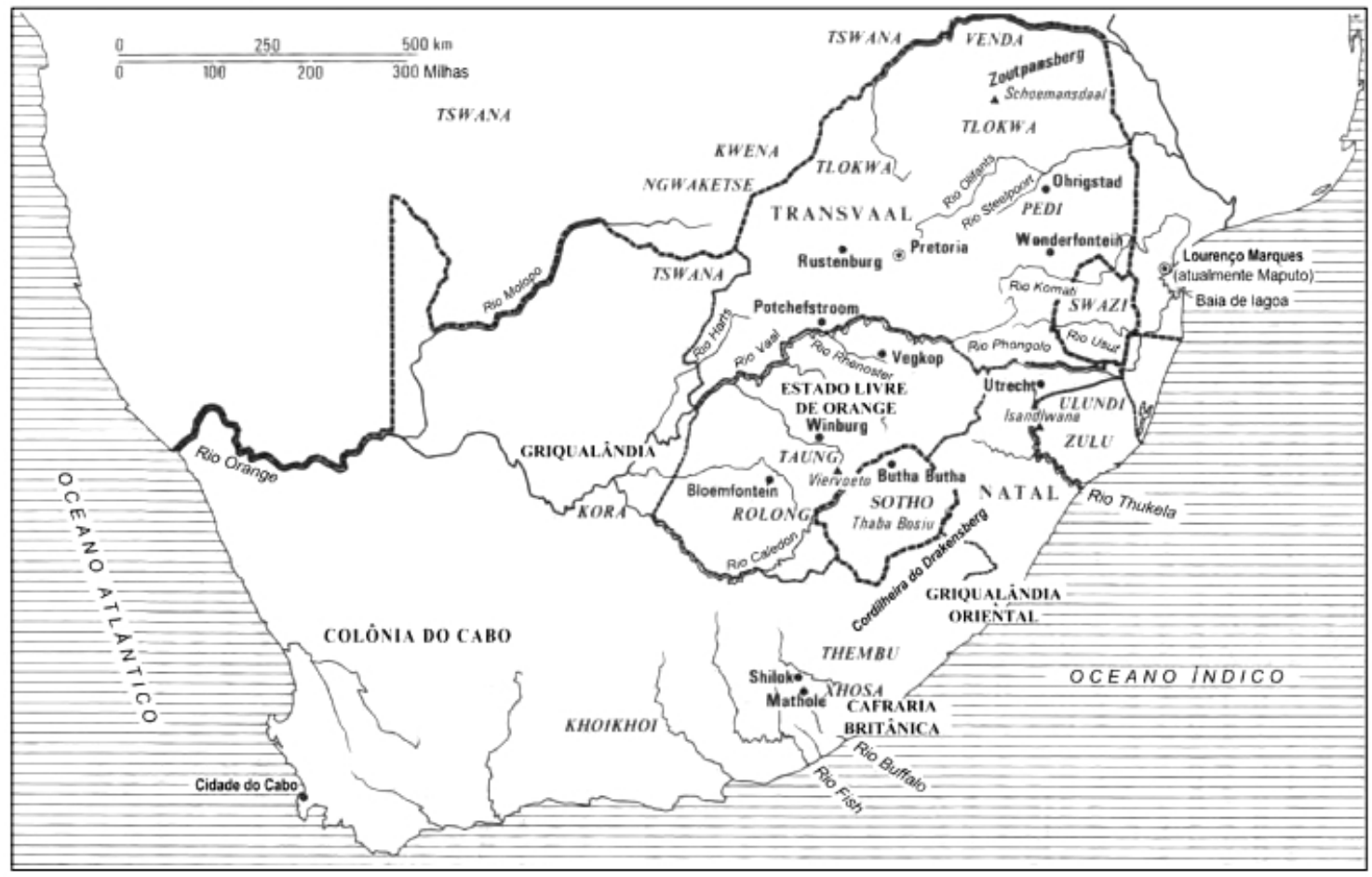

Fonte: BHEBHE, 2010.

Foi no âmago desse contexto sociopolítico e econômico que Howarth migrou para o Cabo Oriental, no sul da África. A despeito da ausência de documentações concernentes às suas tomadas de decisão, elementos contextuais permitem compreender "mudanças de rota, os percalços, os acasos, os possíveis de cada existência" (SCHMIDT, 2014, p.199): o censo populacional de 1851 apresentou um crescimento quantitativo no índice de mulheres entre a população britânica, e, desde aquele momento, a imigração feminina para as colônias passou a ser vista como uma solução para este "problema metropolitano", sobretudo o que se categorizou na época como "mulheres redundantes", isto é, solteiras ou desempregadas (DREHER, 1993, p. 3-4).

Os proponentes dessas políticas de imigração na segunda metade do século XIX argumentavam que o número "anormal" de mulheres britânicas solteiras era um "indicativo de um estado social em desarranjo", sugestivo da sua incapacidade em observar as mulheres em papeis sociais que não fossem o de "mãe, esposa e dona de 
casa". Simultaneamente, a ideia de um excesso feminino apontava para as ansiedades dos setores mais conservadores da sociedade vitoriana diante da possibilidade dessas mulheres ocuparem outras funções sociais e profissionais, tradicionalmente masculinas.

Apesar desses alertas, e da formação de diversas associações imigratórias voltadas para mulheres, as levas migratórias que partiam para as colônias continuavam a ser predominantemente compostas por homens. A região do Cabo Oriental, longe das atividades mineradoras que empregavam massivamente a mão de obra adulta masculina, parecia uma opção mais segura para mulheres como Anna Howarth, oriunda de uma classe média alta; ao mesmo tempo, permitiria à filha de um clérigo a fuga de uma vida de "carnes frias e catecismo, pecadores e salmos" para "vislumbrar no império a radiante esperança de fuga" (MCCLINTOCK, 2010, p. 380).

Ainda assim, a escritora Beatrice Hicks, que viajou pelo Cabo Oriental entre 1894 e 1897, destacou em seus relatos o aspecto pacato da região e a falta de vivências aventurosas, em um claro contraste com a literatura de aventura, principalmente os romances de escritores como H. Rider Haggard e Bertram Mitford, com sua tendência em representar as colônias como espaços de perigo e emoções fortes, possibilidades de enriquecimento rápido, ascensão social e protagonismo político. Foi a partir desse cenário rural que Anna Howarth, em um artigo remetido à revista The Cornill Magazine em julho de 1900, descrevia um cotidiano de "esparsa população" com o "horizonte ilimitável, o senso de distância e isolamento", passível de causar um "efeito depressivo na imaginação do visitante casual" (HOWARTH, 1900, p. 118).

Diante da carência de vivências aventurosas, Howarth ambientou seus romances, e especificamente Sword and Assegai, em episódios passados que envolviam "perigo e aventura", "incidentes emocionantes" e "fugas por um triz", sobretudo nos "dias tempestuosos" das guerras das fronteiras Anglo-Xhosa entre as décadas de 1830 a 1840 (HOWARTH, 1899, p. i). Por esse motivo, os romances de Howarth configuram exemplos de fontes literárias produzidas nos laços interculturais gestados a partir das "zonas de contato", isto é, "espaços sociais onde culturas díspares se encontram, se chocam, se entrelaçam uma com a outra, frequentemente em relações extremamente assimétricas de dominação e subordinação", ao exemplo do "colonialismo, o escravismo ou seus sucedâneos ora praticados em todo o mundo" (PRATT, 1999, p. 27). Trata-se de figurações literárias marcadas pela experiência do colonialismo britânico, informadas por posições de classe social, raça e gênero dos sujeitos históricos em questão. 
A análise em questão, a partir de pressupostos teórico-metodológicos inspirados na história social da cultura e nos estudos africanos, concentra-se na fonte literária em favor de uma análise atenta ao lugar dos textos enquanto parte integrante das ações dos atores sociais, em especial, em seu papel de compreensão dos processos históricos (REVEL, 2009, p. 109). A problematização das guerras das fronteiras em Sword and Assegai, mormente a caracterização da ação dos guerreiros Xhosa, articula-se a um esforço de compreensão do papel da imaginação literária na construção dos sistemas coloniais, em interlocução, "segundo as circunstâncias, aos diversos aspectos políticos, jurídicos e administrativos" (BALANDIER, 1993, p. 109).

Afinal, o colonialismo em África resultou de uma rede intrincada de processos e encontros com "formas alternativas de autoridade, conhecimento e poder" (MCCLINTOCK, 2010, p. 38), os quais também promoveram "processos de mutação cultural e inquieta (des)continuidade que ultrapassam o discurso racial e evitam a captura por seus agentes" (GILROY, 2001, p. 35) - enfim, uma situação histórica contestada, em conflito, mesmo que em um contexto de fortes hierarquias e desigualdades de poder político.

A produção literária configura-se, portanto, como foco da análise a partir de uma chave de interpretação social e política, para pensar os entrecruzamentos, interações culturais e relações simbióticas entre o documento e as circunstâncias de seu tempo. Dessa forma, o estudo crítico de Sword and Assegai circunscreve-o ao momento de institucionalização de leis de terras e trabalho voltadas ao cerceamento da ação política de africanos negros, para assim mapear a trama literária nos movimentos de seu tempo, em um vai-e-vem entre texto e contexto, observando o romance como um rastro fragmentário de razões e paixões políticas cultivadas por Anna Howarth e muitos dos seus contemporâneos no sul da África ao final do século XIX.

\section{Entre a espada e a azagaia}

Sword and Assegai é um romance de aventura centrado principalmente na região de Grahamstown, no interior do Cabo Oriental, entre 1834 e 1853. Na trama, acompanhamos a saga de Maurice Brownlow, um menino órfão que perde toda a família, com exceção da irmã Emily, na guerra de 1834. Com o passar dos anos, Brownlow passa a trabalhar na próspera fazenda de sua família, e envolve-se em negócios altamente duvidosos com um homem chamado John Ellis, que, ao longo da narrativa, descobrimos tratar-se de um contrabandista de tabaco e conhaque, com um 
histórico de aplicar golpes em jovens e inexperientes colonos. Também somos apresentados a outros personagens que se envolvem na trajetória de Brownlow, tais como o laborioso e valente fazendeiro Fred Marston, e o enigmático Willis, um imigrante britânico anteriormente vitimado pelos golpes de John Ellis.

A rotina pacata nas fazendas é interrompida pela guerra de 1846-1847, a chamada "guerra do machado", que acaba afetando, direta ou indiretamente, todos os personagens do romance, convertendo esse grupo de colonos e fazendeiros à ação militar. Não há tesouros escondidos ou civilizações perdidas em Sword and Assegai, mas Brownlow é injustamente acusado pelo roubo de uma caixa de joias em decorrência dos crimes de Ellis; esse episódio acaba aproximando Brownlow de uma família de colonos, os Farrer, forçados a abandonar sua fazenda constantemente devido aos ataques Xhosa.

Como se pode ver, Howarth mobiliza o romance de aventura para narrar uma história do protagonismo britânico no processo de ocupação colonial e apropriação das terras dos Xhosa no sul da África. Essas produções literárias associavam-se ao recrudescimento das práticas políticas coloniais entre as décadas de 1870 e 1880, e desencadearam uma nova semântica em torno da ideia de aventura e da figura do aventureiro (VENAYRE, 2001).

Desempenhavam um papel nada desprezível na formação de gostos estéticos e sensibilidades políticas de seu público leitor, na medida em que, por meio de suas tramas e personagens, cingiam razões e sentimentos associados às práticas políticas coloniais e, ao mobilizar preceitos raciais ou racistas na construção de seus personagens, sobretudo de africanos negros, formulavam alteridades convenientes que visavam legitimar a conquista imperialista de novos territórios. Com efeito, Howarth frequentemente reforça estereótipos raciais ao descrever seus personagens a partir de termos atualmente considerados pejorativos, caracterizando-os como "furtivos e bárbaros", ou ainda demonizados enquanto "inumeráveis, irresistíveis, feito demônios das bocas de Gehenna" (HOWARTH, 1899, p. 13-14).

Os romances de aventura, ao enredarem tramas repletas de perigos e cenários exóticos, atuavam na definição de subjetividades associadas à "virilidade em situação colonial" (TARAUD, 2013). Ademais, no final do século XIX, a literatura aventuresca era compreendida como um gênero literário não apenas masculino, como também voltado à redefinição de uma masculinidade branca e colonial, sobretudo vinculada ao protagonismo social e político classes médias e elites (SHOWALTER, 1994). A escolha 
pelo romance de aventura parece demarcar um esforço duplo por parte da romancista: em primeiro lugar, de inserir-se em um campo literário que era, no final do século XIX, visto como caracteristicamente masculino; e, em segundo lugar, constituir novas formas de ação política e atuação pública, principalmente ligadas ao colonialismo, e que fossem compatíveis com atividades historicamente associadas às mulheres de classe média e educadas - nesse caso, a enfermagem, uma atividade profissional que, naquele período, era atrelada a um campo mais amplo do "cuidado com crianças, doentes e os idosos ou, mais comumente, com as pessoas categorizadas como pobres, as que não têm as condições mínimas para sobreviver e precisam daqueles que podem oferecer-lhes essas condições" (MARTINS, 2011, p. 17).

Ao pensar a inserção política de Anna Howarth a partir de sua escrita literária, a ênfase recai sobre as representações das guerras nas fronteiras do Cabo Oriental e das populações Xhosa no romance, afinal, essas figurações literárias das populações africanas negras tinham um papel importante na legitimação pública do colonialismo. Nesse ponto, é preciso lembrar que, historicamente, a região fronteiriça era considerada pelas comunidades Xhosa como parte de suas terras ancestrais, das quais haviam sido privados pela expansão contínua da Colônia do Cabo, principalmente nas décadas de 1820 a 1840. Por essa razão, os Xhosa continuaram a fazer uso das terras para pastoreio e caça, desafiando as autoridades coloniais do Cabo.

Esse uso das terras, com base no direito consuetudinário e nos costumes ancestrais, era por vezes acompanhada de roubos de gados, movimentos que os colonos brancos respondiam por meio de ataques de represália sobre as terras Xhosa. Portanto, no âmago dos conflitos entre 1834 e 1853, jazia a questão da terra e do gado, que afetavam diretamente os dois principais grupos Xhosa na região oriental do Cabo: os Gcaleka e os Rarhabe (esses últimos divididos em dois subgrupos: os Ngqika e os Ndlambe). Além disso, os conflitos se inseriam num quadro mais amplo de tensões nas fronteiras desde o final do século XVIII, motivadas "pela hostilidade dos Xhosa ao insidioso esbulho de suas terras; franqueamento ilícito da fronteira por uns ou por outros; roubos recíprocos de gado; represálias, contra-represálias e contestações intermináveis" (M’BOKOLO, 2009, p. 302).

Documentos redigidos no período, ao exemplo do relato de Robert Godlonton, $A$ Narrative of the Irruption of the Kaffir Hordes Into the Eastern Province of the Cape of Good Hope de 1835, reforçavam a imagem dos Xhosa como traiçoeiros e incivilizados, insubordinados e naturalmente condicionados a violência. Esses documentos atuavam 
como "instrumentos que permitiam o domínio britânico", pois forneciam "um sistema de conhecimento que possibilitava os britânicos a explicarem a si mesmos porque era legítimo seu governo sobre os Xhosa, e porque era justificável, em última medida, a destruição da cultura cívica dos Xhosa” (PRICE, 2008, p. 164-165). Um dos efeitos dessas circunstâncias foi a criação da Província de Queen Adelaide em 1835, com a intenção de submeter a autoridade das chefias Xhosa à lei britânica, o que marcou uma primeira tentativa de impor um sistema de governo colonial sobre um conjunto amplo de linhagens africanas independentes localizadas em um território demarcado.

Como essas questões informavam a escrita literária de Anna Howarth, ao tratar sobre as guerras nas fronteiras e as lutas dos Xhosa por suas terras e independência? Sword and Assegai, inicia-se ao final da guerra de 1834-1836, e que foi causada em reação à tomada de terras e gado dos Xhosa (sobretudo dos Rarhabe) e pela captura, seguida da escravização, de mulheres e crianças Xhosa pelos colonos brancos. As forças Xhosa foram lideradas por Maqoma, um chefe Rarhabe, que havia sido constante alvo de perseguições e expulsões das suas terras; em questão de poucos meses, as tropas coloniais também avançaram sobre os Gcaleka, acusados de terem se aliado e apoiado os Rarhabe.

Os conflitos levaram à morte de Hintsa kaKhawuta, o chefe dos Xhosa Gcaleka, a criação da Província de Queen Adelaide (também conhecida como British Kaffraria), e a apropriação de gado e terras dos Xhosa como "compensação" aos danos ocasionados durante a guerra. A escolha de Howarth em ambientar o romance em Grahamstown é bastante significativa, já que a região concentrava uma "facção" influente de fazendeiros brancos altamente interessados em expandir suas terras para a agricultura e pecuária, amparados em uma legislação de terras voltadas à proteção da propriedade privada (WEBSTER, 1991, p. 59).

Na cena inicial do romance, Howarth contrasta o cenário natural do interior do Cabo Oriental, as suas "flores brancas e o jasmim selvagem, e os arbustos escarlates e roseados de gerânio" (HOWARTH, 1899, p. 1), com a violência e a destruição deixada pelos Xhosa sobre as propriedades dos colonos. Howarth evoca a imagem da fazenda arruinada, da qual "nada havia sido deixado exceto as marcas da sua destruição" (HOWARTH, 1899, p. 1). Os leitores são imediatamente apresentados aos colonos convertidos em soldados em defesa de suas terras, em especial Maurice Brownlow Sr., seu filho Alfred, o primo John Ellis e o fazendeiro Luke Farrer: Howarth contextualizaos como imigrantes britânicos da década de 1820, que deixaram a Inglaterra em busca 
de oportunidades de vida em uma terra "cercada por perigos desconhecidos, por animais selvagens e povos selvagens" (HOWARTH, 1899, p. 5).

Ao trabalho, empreendedorismo e dedicação dos colonos britânicos, capazes de “acumular rebanhos e manadas; construir confortáveis lares e plantar frutas", Howarth contrapõe o avanço dos Xhosa: "feito um rio caudaloso, como uma nuvem de gafanhotos destruidores, como se o inferno tivesse sido aberto, eles invadiram a colônia aos milhares [...] Fazendeiros, com suas famílias inteiras, foram massacrados em seus lares, sem uma chance de resistência" (HOWARTH, 1899, p. 8).

A morte dos colonos é utilizada por Howarth como um exemplo da violência associada aos Xhosa, bem como o resultado dos conflitos por terras no Cabo Oriental, contrapondo o sistema tradicional de terras comunais dos Xhosa ao sistema de propriedades privadas implementado pelo colonato branco ao longo do século XIX. A apropriação de terras nativas por colonos bôeres e britânicos é vista por Howarth como justa e necessária para manter a harmonia social, principalmente com base numa ideia de melhoramento das terras voltada ao enriquecimento desses pequenos agricultores brancos: após o fim da guerra de 1834, os colonos "retornaram às suas fazendas e reconstruíram suas casas arruinadas, com o espírito inconquistável” (HOWARTH, 1899, p. 28).

A despeito da relativa tranquilidade nas fazendas, Howarth remete-se "às fronteiras, onde as coisas estavam longe de serem resolvidas. Constantes ataques eram promovidos pelos nativos; cá um cavalo era roubado, acolá algum gado e ovelhas, e os ladrões desapareciam antes que qualquer um pudesse impedi-los" (HOWARTH, 1899, p. 47). Como se pode ver, em defesa das propriedades dos fazendeiros brancos, Howarth contrasta a ação violenta dos Xhosa, descrita pela romancista como atos de "barbarismo" motivados por determinismo raciais, e não do que realmente eram: formas de reivindicação de terras ancestrais, movimentos de protesto social contra a presença colonial, a apropriação das terras e do trabalho nativo. Afinal, em oposição aos Xhosa, Howarth apresenta uma série de personagens negros, especialmente Khoekhoen e Mfengus empregados nas fazendas dos colonos brancos, e descritos como "bons selvagens", isto é, coniventes com o projeto colonial do Cabo.

Nesse sentido, é bastante representativo o diálogo entre John Ellis, Maurice Brownlow e Fred Marston, onde discute-se não apenas a apropriação de terras dos Xhosa - como também a mão de obra e a escravização de nativos: 
"Foi um grande erro", observou Ellis, "libertar os escravos".

"Um grande erro!", exclamou Maurice.

"Sim", disse Ellis, "nós deveríamos escravizar todos eles, ao invés disso. Dê a um negro a independência, e você coloca na mão dele uma arma contra você. Eles agora somam-se aos milhares, e nós somos meia-dúzia".

[...]

"Eu não sei porque deveríamos, mas deveríamos", respondeu Ellis, de forma seca. "Essa terra que você vive pertencia aos nativos outrora. Quais negócios você tem aqui?"

"Eu não tirei ela dos nativos", argumentou Maurice.

"Mas alguém o fez".

"O que não tem nada a ver com a questão da escravidão, entretanto", disse Marston. "O problema da conquista das nações incivilizadas pelos civilizados é dificilmente algo a ser discutido quando estamos prestes a lutar pela nossa pele. Veja os Fengus: eles eram escravos dos Ama-Xhosa, e nós os libertamos; eles serão fieis a nós, como você verá" (HOWARTH, 1899, p. 82-83).

O episódio em questão evidencia alguns dos pilares do projeto colonial de parte da elite do Cabo ao longo do século XIX: o colonialismo, imaginado como uma força justa e benevolente, capaz de proteger e amparar a população nativa, ao mesmo tempo em que se apropriando das suas terras para garantir "a conquista das nações incivilizadas pelos civilizados". Dentro dessa visão de mundo, a suposta benevolência de agentes coloniais implicava na gratidão dos povos conquistados: ao se referir à fidelidade dos povos Mfengu, Howarth aludia à prestação de serviços, na condição compulsória, como lacaios e capatazes nas fazendas pertencentes ao colonato branco, ou, em situações de conflito, como "bons soldados" (HOWARTH, 1899, p. 234), recebendo, em troca parte das terras anteriormente ocupadas pelos Xhosa (VAIL, 1991).

Além do mais, é preciso denotar que, na narrativa literária, Howarth reforça a ideia de que os Mfengu eram "escravos dos Ama-Xhosa, e nós os libertamos”, em alusão à ação de missionários protestantes que teriam amparado e "libertado" do chefe dos Gcaleka, Hintsa. Contudo, a historiografia recente tem problematizado essa caracterização das relações entre os Mfengu e Gcaleka como parte do discurso colonial que enfatizava o "barbarismo" Xhosa: tudo indica que, até a década de 1830, as linhagens Mfengu (compostas, provavelmente, por populações de origens muito diversas - tais como Thembu, Mpondo e até mesmo dos próprios Gcaleka) deslocaramse rumo às terras Xhosa, e estavam sob a esfera de influência política dos Gcaleka, como subordinados ou em processo de assimilação, e não necessariamente como escravos. A intervenção dos missionários em meados dos anos de 1830 levou à migração de Mfengu acompanhados por cerca de 22 mil cabeças de gado pertencentes 
aos Gcaleka rumo a terras anteriormente ocupadas pelos Xhosa Ngqika, o que teria causado a deterioração nas relações entre esses povos (MVENENE, 2014).

Ao avançar a narrativa literária, Anna Howarth busca estabelecer quadros explicativos à guerra de 1846-1847, conhecida nos discursos coloniais da época como "a guerra do machado", que teria oposto os Xhosa Ngqika (Rarhabe), liderados pelo chefe Mgolombane Sandile, aos colonos do Cabo Oriental, auxiliados por milícias nativas compostas por contingentes de Mfengu e Khoekhoen (sobretudo oriundos do assentamento de Kat River). A historiografia recente tem apontado uma série de fatores associados às tensões entre os Xhosa e o colonato branco na década de 1840, incluindo um acirramento nas disputas por terras em decorrência de secas. Afinal, "as guerras entre a Colônia e os Xhosa eram, no final das contas, sobre terras, embora também fossem, em certo nível, sobre mão de obra" (ROSS, 2003, p. 122). É nesse ponto que Howarth alinha-se aos interesses dos colonos no Cabo, especialmente em defesa de maior autonomia política, sobretudo no tratamento da questão nativa: “'depois de tudo', disse Maurice, após uma pausa, 'acredito que não podemos culpar os nativos. Eles são apenas selvagens, e nos observam como intrusos que chegaram e retiraram a terra deles" (HOWARTH, 1899, p. 218).

A apropriação das terras nativas, e o direito dos colonos ao seu uso, novamente parece estar no centro das preocupações de Howarth ao narrar as guerras Xhosa; no contexto da guerra, seus personagens afirmam que "tudo o que queremos é segurança para a vida e a propriedade" (HOWARTH, 1899, p. 217). Certamente, Howarth não estava sozinha na questão, já que a demarcação e expropriação das propriedades comunais da população nativa nos territórios sul-africanos, e principalmente na Colônia do Cabo, era uma temática recorrente nos debates políticos das décadas de 1880 e 1890. A representação dos Xhosa como "bárbaros" e "selvagens", ou ainda como "raças incivilizadas", estava enraizada nos preceitos raciais que informavam o arcabouço imaginário e as práticas políticas de muitos literatos da geração de Howarth. Adicionalmente, uma das circunstâncias históricas que contribui para uma compreensão dos contextos culturais e das redes de interlocução de Sword and Assegai encontra-se na legislação colonial em vigência desde 1894, o Glen Grey Act, e que afetou diretamente as sociedades Xhosa localizadas no Cabo Oriental. 


\section{“A terra é o melhor investimento": legislação de terras e o Glen Grey Act (1894)}

Idealizado pelo então primeiro-ministro da Colônia do Cabo e "magnata da mineração" (randlord) Cecil Rhodes, o Ato 25 de 1894, mais popularmente conhecido como Glen Grey Act, tem sido apontado pela historiografia recente como um dos marcos iniciais das leis de caráter segregacionista nos territórios sul-africanos. Em sua formulação, o Glen Grey Act levava em consideração os resultados de duas comissões instauradas pelo governo colonial: a Cape Comission on Native Laws, de 1883, e a Glen Grey Comission, de 1893. Localizado na parte oriental da Colônia do Cabo, nas proximidades de Queenstown, o distrito de Glen Grey foi estabelecido em 1879 numa região fértil, e bastante favorável às atividades agrárias e ao pastoreio pela presença de vales e rios. Foi a partir desta região que Rhodes implementou a lei, com esperanças de que, eventualmente, poderia ser aplicada a outros pontos da colônia (GOMES, 2015, p. $133)$.

Em seu texto, o Glen Grey Act visava cumprir diversos objetivos vinculados à demarcação das terras e a relação das populações nativas com as posses comunais. Em primeiro lugar, implementava um sistema de divisão de propriedades em porções de aproximadamente 4 morgens $^{3}$ para cada ocupante sob aprovação do governo, transmissíveis apenas em princípio de primogenitura. A lei também estabelecia que as terras só poderiam ser revendidas para outros nativos sob autorização do governo colonial, impossibilitando também o arrendamento para outros agricultores. O princípio de primogenitura, isto é, a ideia de que, em âmbito familiar, a propriedade seria transmitida apenas ao primeiro filho homem do proprietário, implicava na formação de um amplo contingente de africanos negros sem terras ou propriedades, obrigados a buscar empregos na colônia, especialmente nas fazendas de colonos brancos e na mineração de ouro e diamantes (BOUCH, 1993, p. 1-3). Um item adicional à lei, um imposto per-capita de 10 xelins, reforçaria a busca por trabalho remunerado para essa população masculina sem-terra.

Na década de 1890, o controle da mão de obra africana negra tornou-se um dos principais impasses entre os legisladores nas colônias sul-africanas, especialmente no Cabo, onde a "tradição liberal" havia inviabilizado o uso do trabalho compulsório. As demandas por um melhor controle da população nativa e da sua atividade agrícola também cresciam entre os políticos afrikaners, contrários ao uso de reservas e à posse

\footnotetext{
${ }^{3} \mathrm{Na}$ África do Sul, 1 morgen equivale a cerca de 0,85 hectare.
} 
comunal das terras, bem como aos sistemas tradicionais de sociedade e política baseados nas linhagens e na poligamia. Nesse contexto político, a figura de Cecil Rhodes assume uma posição emblemática: enquanto um randlord, atuando principalmente na exploração de diamantes em Kimberley, a sua companhia De Beers Consolidated Mines fazia amplo uso do trabalho migrante africano, controlado principalmente por meio do estabelecimento do sistema de passes, contratos individuais, pela disciplina fabril instaurada nos compounds, além da exclusão de africanos negros dos direitos políticos (GILIOMEE, 2011, p. 290-291).

Desde que foi eleito para o cargo de primeiro-ministro em 1890, Rhodes empreendeu uma política anexacionista voltada à aquisição de territórios nativos, para assim controlar os fluxos de trabalho migrante no interior da Colônia do Cabo. Em 1894, Rhodes anexou a Pondolândia, o último território nativo independente, localizado entre o Cabo e a Colônia de Natal; a ação garantia um acréscimo de aproximadamente 400 mil africanos negros à população da colônia. O período marcou uma aproximação de Rhodes ao Afrikaner Bond, partido fundado na década de 1880 com o objetivo de defender os interesses culturais e políticos de afrikaners diante da crescente esfera de influência britânica. Essa aproximação também envolvia a idealização de legislações de terra que garantisse não apenas o controle do colonato branco, mas que fosse capaz de barrar os direitos políticos da população nativa em posse comunal de terras.

O Glen Grey Act não havia sido o primeiro esforço em produzir leis que estruturassem a relação entre a população sul-africana negra e o uso ou a posse de terras, e faz parte de um conjunto maior de medidas adotadas pelo Estado colonial no "processo de proletarização" de africanos (AJAYI, 2010, p. 922), baseado na expropriação de terras previamente pertencentes a reinos, linhagens ou chefias africanas, o que criaria um vasto número de populações sem-terra, deixados sem escolha a não ser trabalharem em condições rigorosas fixadas por seus rivais brancos.

A primeira de uma série de leis foi o Native Locations Land and Commonage Act n. 40 of 1879, que, em sua primeira seção, conferia ao governo o direito de demarcar territórios naquelas consideradas 'terras vagas' na colônia” (GOMES, 2015, p. 134). A partir dessa medida, a terra deveria ser dividida em lotes distribuídos àqueles considerados pelo governo colonial como financeiramente suficientes para arcar com os custos. Aplicada de forma experimental ao assentamento de Kat River, uma região do Cabo Oriental com um histórico de disputas entre nativos e colonos brancos por terras, a lei também previa a criação de áreas comunais para a pastagem de gado. 
Nesse ponto, é importante demarcar que, assim como o Glen Grey Act, a lei de 1879 tocava diretamente no controle de mão de obra, principalmente para a indústria mineradora: os nativos que não fossem considerados como aptos a receber lotes de terras seriam obrigados a encontrar outras formas de subsistência além da agricultura ou do pastoreio. Além disso, no mesmo dia de aprovação da lei de 1879 , foi publicado o First Vagrancy Act n. 23, que definia a "vadiagem": todos aqueles que não tivessem meios de sustentação ou estivessem longe de seu território de origem. Somado ao contexto mais amplo, de preocupação com o fluxo de mão de obra nativa, as duas leis indicavam a possibilidade do deslocamento de nativos dos seus territórios originais para áreas onde fossem empregados a serviço do colonato branco (ELIAS, 1984, p. 3-5).

O pequeno distrito de Glen Grey tornou-se o ponto de partida da lei de 1894. Localizado ao norte de Queenstown, as terras de Glen Grey haviam sido designadas, no início da década de 1850, aos Thembu, povos de cultura e falantes das línguas Xhosa, no processo de demarcação de fronteiras após a oitava guerra das fronteiras (18501853). Nas suas origens, o distrito abrigava quatro chefias Xhosa, simbolicamente sob a autoridade de uKumkanikazi Nonese, mas supervisionados de facto por um agente colonial, o ex-missionário Joseph Warner (MVENENE, 2020, p. 122-123).

Em 1889, uma petição enviada por colonos brancos no distrito de Glen Grey, Wodehouse e Queenstown ao conselho legislativo do Cabo demandava a retirada dos abaThembu, permitindo assim a aquisição das terras por fazendeiros brancos. Dessa forma, embora passível de ser aplicável a outros territórios da Colônia, o Glen Grey, em sua idealização, concentrava-se nesse pequeno distrito do Cabo Oriental, e voltado especificamente para a população Xhosa que aí residia.

“A terra é o melhor investimento" (HOWARTH, 1899, p. 291), afirma um dos personagens de Anna Howarth em Sword and Assegai. Para tanto, conclui outro personagem, "os nativos não nos deixariam viver em paz, e nós temos que subjugá-los ou deixar o país" (HOWARTH, 1899, p. 219). Quando observado à luz da legislação de terras em vigência no período, a escolha pelo tema e pela tonalidade política pela romancista parece enquadrar-se nos debates contemporâneos, em especial, à apropriação de terras e ao controle da mão de obra nativa.

Tanto a Native Locations Land and Commonage Act de 1879 quanto o Glen Grey Act de 1894 embasavam-se em uma crença de que "sistemas de posse individual de terra instituiriam um melhor controle dos nativos e de sua atividade agrícola argumento que pode ser questionado, entre outros pontos, porque assume a ideia de que 
a promulgação de uma lei é seguida por seu cumprimento ipsis litteris, sem encará-lo como algo fluido e de negociação cotidiana" (GOMES, 2015, p. 134).

Alinhavando-se a esse momento da legislação colonial no Cabo, Howarth produziu uma narrativa literária que contrapunha o "mau uso" da terra pelos Xhosa com o empreendedorismo do colonato branco: tanto que, no desfecho do romance, as terras apropriadas pelos fazendeiros britânicos evidenciavam "um jardim fértil, sorridente, um córrego de água pura e cristalina, manadas de gado lustroso", além da "felicidade doméstica, de afeição constante e duradora” (HOWARTH, 1899, p. 344).

Além dos efeitos econômicos sobre os africanos negros, o Glen Grey Act causou impactos culturais, em especial, a negação de espaços de ancestralidade e comunidade vinculados ao uso comunal das terras. Tudo indica que, em reverberação ao projeto de segregação territorial implementado durante a década de 1890, Anna Howarth mobiliza a obra literária como uma espécie de justificativa política para a ação da legislação de terras: enfatizar o "barbarismo" dos Xhosa durante a guerra para legitimar a apropriação das terras ancestrais e a desarticulação identitária que passa pela inserção do nativo na economia monetária para atender as demandas da elite colonial.

Entrelaçada à defesa pela expropriação das terras para fins agrícolas e por medidas mais eficazes de controle da população africana, sobretudo dos Xhosa, Howarth recorre, com certa frequência, em defesa do governo colonial no Cabo, contrapondo-o às decisões adotadas pelo secretariado de colônias em Londres. Direta ou indiretamente, Howarth mobiliza o texto literário para destacar o papel do governo local em garantir a segurança do colonato branco nas fronteiras por meio de medidas que "dêem limites aos nativos", "leis justas", tais como a proibição do consumo de álcool ou do porte de armas de fogo: "se eles apenas permitissem que governemos a nós mesmos, poderíamos lidar muito melhor" (HOWARTH, 1899, p. 217).

Para justificar a ação do Estado colonial, Howarth reforça a crença no "fardo do homem branco", expressão cunhada pelo "poeta do Império", Rudyard Kipling, no final do século XIX, para aludir ao suposto papel civilizatório do colonialismo europeu. Segundo Howarth, não restavam dúvidas: "há algumas raças que não possuem nenhum impulso ao progresso; elas vivem em uma terra fértil e valiosa por centenas de gerações, sem sequer desenvolver seus recursos [...]. No final, elas devem ser expulsas por aquelas que podem e irão" (HOWARTH, 1899, p. 218). 


\section{Considerações Finais}

Por meio do romance de aventura, um gênero literário de ampla circulação nas últimas décadas do século XIX, Anna Howarth promoveu uma reflexão acerca da formação da sociedade colonial no sul da África, com ênfase na ação do colonato branco, em especial de fazendeiros britânicos no Cabo Oriental, e no combate aos Xhosa, descritos na trama literária como indivíduos "bárbaros" e "selvagens".

A caracterização dos Xhosa, mormente dos Ngqika e Rarhabe no contexto das guerras de fronteiras entre as décadas de 1830 a 1850, estava entrelaçada aos discursos raciais e estereótipos racistas frequentemente mobilizados pela ideologia colonialista do final do século. Além disso, na trama literária de Howarth, a ênfase no "barbarismo" dos Xhosa atrelava-se a uma dimensão socioeconômica: como uma forma de álibi político do colonialismo, uma justificativa para a apropriação das terras ancestrais de africanos negros e o seu enquadramento à sociedade colonial na condição de mão-deobra.

Ao remeter seus leitores às décadas de 1830 a 1850, Howarth enfatiza a ação de pequenos e laboriosos colonos, convertidos em bravos soldados, na defesa e na demarcação das fronteiras da região oriental da Colônia do Cabo, o que implicava na tomada das terras e do gado das sociedades Xhosa, que possuíam uma presença histórica naqueles territórios. Nesse sentido, Howarth adota uma tonalidade política prócolonial, ou seja, favorável à administração colonial no Cabo, principalmente na formulação de códigos jurídicos e sistemas legislativos que estabelecessem um controle mais eficaz sobre as populações nativas. Por esse motivo, o romance alinha-se a uma série de medidas adotadas na década de 1890, sobretudo o Glen Grey Act de 1894, formulado com o objetivo de limitar o acesso da população negra às terras comunais, desarticulando, ao mesmo tempo, formas tradicionais de comunidade.

Diante da situação colonial, da perda de suas terras ou da sua autonomia política, bem como dos processos de exploração do trabalho e da mão de obra, as sociedades e culturas africanas promoveram um vasto leque de reações e resistências (CHANAIWA, 2010). Do ponto de vista da elite colonial, na visão partilhada por Howarth em Sword and Assegai, os conflitos nas fronteiras do Cabo Oriental eram causados pelo "barbarismo" dos Xhosa, responsáveis por invasões de terras, captura de gados e a mortandade de colonos; essa visão estava entrelaçada ao discurso colonial, num esforço 
de legitimar a tomada das terras dos Xhosa, processo posto em ação desde o início do século XIX.

Na contracorrente dessa perspectiva, e a partir de uma perspectiva crítica diante de textos e imagens produzidos no período colonial, a historiografia recente tem promovido novas interpretações das guerras nas fronteiras: como iniciativas políticas, formas de resistências dos povos Xhosa diante dos avanços do projeto colonial no Cabo.

\section{Referências}

\section{Fontes:}

HOWARTH, Anna. Sword and Assegai. Londres: Smith, Elder \& Co., 1899.

HOWARTH, Anna. The Boer at Home. The Cornhill Magazine, v. 9, n. 49, pp. 118126, jul.1900.

HOWARTH, Anna (Pseudônimo: Anglo-Africana). Coronation Ode. Good Words, v. 43, pp. 53-55, dez. 1902.

\section{Bibliografia:}

AJAYI, Jacob Adeniyi. A África às vésperas da conquista europeia. In: AJAYI, Jacob Adeniyi. (org.). História Geral da África: África do século XIX à década de 1880. Brasília: UNESCO, 2010.

BHEBE, Ngwabi. Os britânicos, os bôeres e os africanos na África do Sul, 1850-1880. In: AJAYI, Jacob Adeniyi. (org.). História Geral da África: África do século XIX à década de 1880. Brasília: UNESCO, 2010.

BOUCH, Richard. Glen Grey before Cecil Rhodes: How a Crisis of Local Colonial Authority Led to the Glen Grey Act of 1894. Canadian Journal of African Studies, Toronto, v. 27, pp.1-24, 1993.

CHANAIWA, David. Iniciativas e resistências na África meridional. In: BOAHEN, Albert Adu (org.). História Geral da áfrica: África sob dominação colonial, 1880-1935. Brasília: UNESCO, 2010.

DREHER, Nan. Redundancy and Emigration: The 'Woman Question' in Mid-Victorian Britain. Victorian Periodicals Review, Baltimore, v. 26, n.1, pp. 3-7, 1993.

ELIAS, Christiane. A Housing Study: Legislation and Control of the Supply of Urban African Accomodation. Second Carnegie Inquirt Into Poverty and Development in Southern Africa (paper não-publicado), pp.1-43, 1984.

FOURIE, Fiona. A "New Woman" in the Eastern Cape. English in Africa, Makhanda, v. 22, n. 2, pp. 70-88, out. 1995.

GILIOMEE, Hermann. The Afrikaners: Biography of a People. Londres: Hurst \& Company, 2011. 
GILROY, Paul. O Atlântico Negro: modernidade e dupla consciência. São Paulo: Editora 34; Rio de Janeiro: Universidade Cândido Mendes, Centro de Estudos AfroAsiáticos, 2001.

GOMES, Raquel Alves. De Espinhos e Aguilhões: segregação e lei de terras na obra de Sol Plaatje, 1902-1930. Tese (Doutorado em História), Universidade Estadual de Campinas, 2015.

KANIKI, Martin. A economia colonial: as antigas zonas britânicas. In: BOAHEN, Albert Adu. História Geral da África: África sob dominação colonial, 1880-1935. Brasília: UNESCO, 2010.

LEVI, Giovanni. Usos da biografia. In: AMADO, Janaína. FERREIRA, Marieta de Moraes (orgs.). Usos e abusos da história oral. Rio de Janeiro: FGV, 2005.

M'BOKOLO, Elikia. África Negra: História e Civilizações, vol. 2. Salvador: UFBA, 2009.

MAMDANI, Mahmood. Citizen and Subjects: Contemporary Africa and the Legacy of Late Colonialism. Princeton: Princeton University Press, 1996.

MARTINS, Ana Paula Vosne. Gênero e assistência: considerações histórico-conceituais sobre práticas e políticas assistenciais. História, Ciências, Saúde, Rio de Janeiro, v.1, p.15-34, dez. 2011.

MCCLINTOCK, Anne. Couro Imperial: raça, gênero e sexualidade no embate colonial. Campinas: UNICAMP, 2010.

MVENENE, Jongikhaya. A History of the abaThembu People from Earliest Times to 1920. Stellenbosch: African Sun Media, 2020.

PEIRES, Jeffrey. The House of Phalo: A History of the Xhosa People in the Days of their Independence. Berkeley: University of Carolina Press, 1982.

PRATT, Mary Louise. Os olhos do Império: relatos de viagem e transculturação. Tradução de Jézio Hernani Bonfim Gutierre. Bauru: EDUSC, 1999.

PRICE, Richard. Making Empire: Colonial Encounters and the Creation of Imperial Rule in Nineteenth-Century Africa. Cambridge: Cambridge University Press

REVEL, Jacques. Proposições: ensaios de história e historiografia. Rio de Janeiro: EdUERJ, 2009.

ROSS, Robert. Ambiguities of Resistance and Collaboration on Eastern Cape Frontier. In: ABBINK, Jon; DE BRUIJN, Mirjam; VAN WALRAAVEN, Klaus. Rethinking Resistance: Revolt and Violence in African History. Brill: Leiden, 2003. 
SANTOS, Gabriela Aparecida dos. Lança presa ao chão: guerreiros, redes de poder e a construção de Gaza (travessias entre a África do Sul, Moçambique, Suazilândia e Zimbábue - século XIX). Tese (doutorado em História), Universidade de São Paulo, São Paulo, 2017.

SCHMIDT, Benito Bisso. Biografia: um gênero de fronteira entre a história e a literatura. In: RAGO, Margareth (org.). Narrar o passado, repensar a história. Campinas: UNICAMP/IFICH, 2014.

SHOWALTER, Elaine. Anarquia sexual. Rio de Janeiro: Rocco, 1994.

TARAUD, Christelle. A virilidade em situação colonial. In: CORBIN, Alain (org.). História da virilidade: o triunfo da virilidade, o século XIX. Petrópolis: Vozes, 2013.

VAIL, Leroy. Mfengu-Rharhabe Rivalry and the Rise of Lennox Sebe. In: VAIL, Leroy (org.). The Creation of Tribalism in South Africa. Berkeley: University of California Press, 1989.

VENAYRE, Sylvain. Une histoire des representations: l'aventure lointaine dans la France des annés 1850-1940. Cahiers d'histoire. Revue d'histoire critique, Paris, n. 84, p. 93-112, 2001.

WEBSTER, Alan Charles. Land Expropriation and Land Extraction under Cape Colonial Rule: The War of 1835 and the 'Emancipation' of the Fingo. Dissertação (Mestrado em História), Rhodes University, Makhanda, 1991.

Artigo submetido em 30 de maio de 2021. Aceito em 05 de julho de 2021. 